\title{
Location-based Analysis and Optimization of Service Network Performance: A Case Study
}

\author{
Shuo Yang, Hao Yu* and Wei Deng Solvang \\ Department of Industrial Engineering \\ UiT-The Arctic University of Norway \\ Narvik, Norway \\ *Corresponding author: hao.yu@uit.no
}

\begin{abstract}
The location problem of service network has been extensively focused by researchers in operational research due to the difficulty in balancing the level of service and efficiency. On the one hand, installing a large number of service facilities within the service network improves availability and responsiveness to customer demands, but it also increases the investment and operating cost. While on the other hand, opening a limited number of facilities in a service network increases the efficiency with a compromise of responsiveness and customers' satisfaction. In order to balance the level of service and efficiency of a service network, this paper defines three location-based performance indicators with respect to three locations models: availability (set covering location model), efficiency (maximal covering location model), and responsiveness ( $p$-median location model). In order to illustrate a deep managerial insight of real-world application, a case study of postal service network in Narvik is performed latter in this paper.
\end{abstract}

Keywords-Service network; service facility location; opertional research; set covering location model; maximal covering location model; p-median location model

\section{INTRODUCTION}

A service network refers to a series of activities that coordinate the flow of goods, information, financial resources and services among the network of business partners in order to create value for their customers, and the main goal of the service network is to minimize cost while maximizing value creation and efficiency [1]. Service facilities are the most important nodes of a service network, and they provide different kinds of service either to commercial customers (e.g. vehicle maintenance) or for public use (e.g. waste collection points). Due to the significant role in determining the level of service and efficiency of a service network, the location problem of service facilities has been extensively focused and studied by researchers in management science and operational research since the 1960s.

The number and locations of service facilities are the most important decisions in determining the performance of a service network in terms of responsiveness and efficiency [2]. The response time to customer's demands increases with the decrease of the number of service facilities installed. However, in today's competitive business world, customers do not want to travel a very long distance or wait in an endless line; instead, they prefer to be served in a timely and appropriate fashion [3].
This leads to the conflicting objectives between customers and service providers. On the one hand, installing a large number of service facilities within the service network improves availability and responsiveness to customer demands, but it also increases the investment and operating cost. While on the other hand, opening a limited number of facilities in a service network increases the efficiency with a compromise of responsiveness and customers' satisfaction.

In order to balance the level of service and efficiency in an optimal manner, this paper defines three location-based performance indicators: availability, efficiency and responsiveness, respectively. The availability implies whether a service facility is located with the preferred distance of customers. Efficiency refers to the maximum rate of customers' satisfaction a service can deliver with limited number of facilities. Responsiveness is the ability of providing service to customers in a timely manner, which is regard as to minimize to total/average travel distance between customers and service facilities in a location-based analysis.

This paper employs three well-established location models of service network design (set covering, maximal covering and $p$-median) for optimizing the availability, efficiency and responsiveness, respectively. In order to illustrate a deep managerial insight of real-world application, a case study of postal service network in Narvik is performed latter in this paper.

\section{LITERATURE REVIEW}

Modern facility location problem originates from 1909. To obtain the minimum total travel distance between a warehouse and several customers, Alfred Weber established a mathematical model for a median problem in "Euclidean space" [4]. This is the famous Weber problem. Since then, facility location problems has been studied by both researchers and practitioners from different disciplines. In general, facility location problem can be divided into two types: continuous location problem and discrete location problem [5]. Discrete location problem is also known as the vertex location problem where the candidate points of facility are identified beforehand as nodes on a graph [6]. In a discrete location problem, the number of candidate locations is limited [7]. However, the objective of continuous location problem is to "generate" nodes for locating new facilities relative to a set of existing facilities situated in a given space [6]. Continuous location problem is also called absolute location 
problem. In practice, discrete location problem has a much wider range of application, so this paper focuses mainly on this type of location problem.

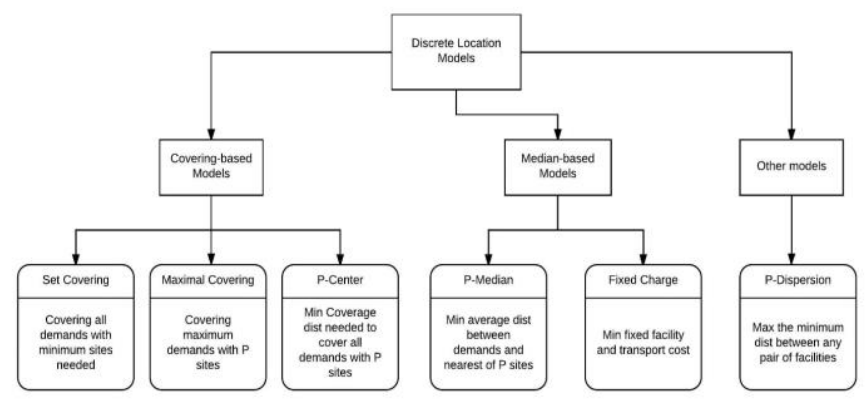

Fig. 1. Three broad aspects of discrete location models [7]

Fig. 1. Shows the classification of discrete location models. According to Daskin [7] and Current [8], demand node is considered to be served if and only if the supposed critical coverage distance or time are "covered" or "served adequately" in the covering-based models [7]. In the median-based models, the weighted demand average distance between a demand site and facility is minimized [7]. Models satisfy neither of the aforementioned features belong to the category of "other models". For instance, $p$-dispersion model which maximizes the minimum distance between any two of facilities. The literature review is given with respect to the three different discrete location problems.

\section{A. The covering-based location models for service network design}

Covering-based models are widely applied in healthcare. Daskin and Dean [9] investigated the location problems of healthcare facilities. They identified three approaches with respect to accessibility, adaptability and availability of healthcare facilities optimized using set covering model, maximal covering model and $p$-median model. Also, to address the question of locating healthcare facilities in a Brazilian city in order to improve the effectiveness, Arnaldo and Iara [10] conducted a research with the aid of $p$-median model, set and maximal covering models and $p$-center model. Brotcorne et al. [11] presented a literature review on the evolution of ambulance location and relocation models with the help of covering-based location models.

To optimize the locations of facilities of medical supplies for large-scale emergencies in Los Angeles area, Ordonez et al. [12] proposed a general facility location model. For maximizing the perinatal care accessibility in France, Baray and Cliquet [13] presents a hierarchical location-allocation model that combines a maximum covering model and $p$-center model. Jia et al. [14] developed models and solutions for determining the locations of medical supply facilities in response to large-scale emergencies in order to address the demand uncertainty and medical supply insufficiency. With the purpose of making the healthcare level becomes more systematic and efficient, Shariff et al. [15] develop a capacitated MCLP (CMCLP) based on the Maximal Covering Location Problem.
Covering-based models are also widely used in military and/or security fields. Dawson [16] aimed to find the optimal placement for one layer of the security net protecting nation's Intercontinental Ballistic Missile (ICBM) through utilizing three locating facility methods: maximum covering location model, $p$ centre model and $p$-median. Similarly, with the aim of the defense of important national areas of interest in the U.S., Bell et al. [17] investigated set covering location problem in order to find the minimum number of alert sites, and then improves result according to a $p$-median solution.

Covering-based models have significant contribution in locating public service facilities as well. Erdemir et al. [18] developed two separate models based on covering models considering a situation that demands occurred on both nodes and paths. For improving the coverage of the demands in emergencies, Batta and Mannur [19] proposed a new criterion for coverage based on the set covering location model and the maximal covering location model. To address the lack of objective quantitative methods for police patrol area, a backup covering location model based on the traditional maximal covering model for determining efficient spatial distributions is presented in Curtin et al. [20]. Balcik and Beamon [21] developed a variant model of maximal covering location model for determining the number and locations of distribution centers in a relief network, which integrates facility locations and inventory decisions under restrictions of both budgetary and capacity.

Some previous research works provide inspirations for the current research. For instance, Revelle et al. [22] investigated that links between the emergency facilities and the cost. In this study, each demand point is specified by time or distance and required to be covered. With the propose of improving the accessibility of post offices, an approach is presented by Sarac et al. [23] for determining the minimum number of postal units. $\mathrm{Yu}$ et al. [3] combined the two concepts of accessibility and efficiency in a printing service network.

\section{B. The median-based location models for service network design}

Median-based models are widely applied in business field. Nozick and Turnquist [24] incorporated both fixed-charge model and $p$-median model for coordinating cost expense and customer responsiveness in order to determine the locations of distribution centers. P-median and un-capacitated fixed charge facility location model were compared by Madleňák et al. [25] for minimizing the average transport cost and overall cost in a postal service network. Analogously, with the aim of minimizing the sum of the setup cost and transportation cost, Dantrakul et al. [26] developed a greedy algorithm with $p$ median and $p$-centre models. García-Palomares et al. [27] developed a GIS-based method to calculate the spatial distribution of the potential demand in order to ensure the locations of bike station are closed to the potential demands. Nozick and Turnquist [28] posed an optimal method for including inventory costs within the fixed-charge facility location model for distribution centers.

To ensure an equitable distribution of services is important in siting facilities, but sometimes capacity limitations at facilities should also be considered [29]. Murray and Gerrard [29] 
introduced a capacitated regionally constrained $p$-median problem together with regional requirements in a locationallocation framework. With the help of $p$-median, $p$-centre and maximal covering location models, a location optimization model was developed by Eberlan [30] to optimally locate the alert sites with minimum number, minimum aggregate network distance and minimized maximum distance given a range of aircraft launch times and speeds. A review of strategic facility location was provided by Oven and Daskin [31], which focus on facility location problems with stochastic and dynamic characteristics.

\section{The other location models for service network design}

Erkut [32] studied $p$-dispersion location problem. The selected points in $p$-dispersion problem are considered as facility sites and the objective is to locate as 'dispersed' a set as possible. Besides, both theoretical and mathematical problems were studied in the paper. Kuby [33] analyzed both $p$-dispersion and maximum dispersion problems, and he argued in this article that $p$-dispersion problem might be useful in finding a starting distance for the series of covering problems.

\section{METHODOLOGY}

\section{A. Set covering location model}

In 1971, the set covering location model was first introduced by Toregas et al. [22] with the propose of finding the minimum number (or cost) of facilities and their locations, so that each node-supplier must serve the facility with the specified maximum response time, distance or radius. It should be noticed that all demand nodes are required to be covered by using set covering location model with the minimum number of facilities. Based on Current et al. [8], the mathematical model of demand weighted set covering location problem can be formulated as follows:

Minimize

$$
\sum_{j \in J} c_{j} x_{j}
$$

Subject to:

$$
\begin{aligned}
& \sum_{j \in N_{i}} x_{j} \geq 1, \forall i \in I \\
& x_{j} \in\{0,1\}, \forall j \in J
\end{aligned}
$$

Herein, $c_{j}$ denotes the cost of construction, and $I$ denote the set of demand nodes, indexed by $i$, and $J$ denotes the set of candidate facility locations, indexed by $j . d_{i j}$ represents the distance between demand node $i$ and candidate facility $j$ and $d_{s}$ represents the distance coverage. Let $N_{i}=\left\{j \mid d_{i j} \leq d_{s}\right\}$ denotes the set of all candidate locations that can cover demand point $i$ and the following decision variable $x_{j}$ is binary decision variable which determines if a potential location $j$ is selected to open a new service facility.

In the set covering location model, the objective of Eq. (1) minimizes the number and cost of located facilities in service network. Eq. (2) guarantees that each demand node is covered by at least one facility. And Eq. (3) enforces 'yes' or 'no' nature of the siting decision.

\section{B. Maximal covering location model}

The precondition of finding minimum number of facilities and their locations through set covering location method is that all of demand points must be covered. However, a budget does exist for the most of cases [8]. When the decision maker does not have enough resources to meet all needs, a workaround is he or she needs. For improving the efficiency of facility usage, decision maker must to locate a fixed number of facilities and the specified maximum response time or desired service distance [34].

Under this circumstance, Church and Velle [35] proposed and formulated the original maximal covering location problem in 1974. Maximal covering location problem aims to locate limited number of facilities $(p)$ to maximize the number of covered demands. This model differentiates between big and small demands and allows some demand needs to be uncovered if the number of facilities needed to cover all demand nodes exceeds $p$. The mathematical model of maximal covering location problem can be formulated as follows:

$$
\text { Maximize } \quad \sum_{i \in I} \sum_{j \in J} w_{i} s_{i j} x_{i j}
$$

Subject to:

$$
\begin{gathered}
\sum_{i \in I} x_{i j}=1, \forall i \in I \\
\sum_{j \in J} y_{j}=P \\
x_{i j} \leq y_{j}, \forall i \in I ; j \in J \\
x_{i j}=\{0,1\}, \forall i \in I ; j \in J \\
y_{j}=\{0,1\}, \forall j \in J
\end{gathered}
$$

Herein, $I$ denotes the total number of demand points, and $w_{i}$ denotes demand at point $i$. $J$ is the number of candidate locations, indexed by $j . d_{i j}$ represents travel distance between point $i$ and $j$. $P$ denotes the number of facility to be located, and $d_{s}$ represents the distance beyond which a demand area is considered uncovered. $x_{i j}, y_{j}$ and $s_{i j}$ are binary parameters, $x_{i j}$ determines if a point is covered by facility that located at point $j, y_{j}$ determines if a facility is located at node $j$, and $s_{i j}$ determines whether $d_{i j} \leq d_{s}$.

In the maximal covering location model, the objective function Eq. (4) maximizes the overall weighted customer demands under the coverage of service network. Eq. (5) ensures that each demand point is served by one facility. Eq. (6) rules that there are exactly $p$ facilities will be opened. Eq. (7) guarantees that each demand point can be covered. Due to maximal covering location problem is an integer programming problem, Eq. (8) and Eq. (9) make sure that the variables are integers. The maximal location problem determines the locations of $p$ service facilities so that the total weighted-demand coverage is maximized [31]. 


\section{P-median location model}

In order to analyze the accessibility of service facility, $p$ median location model is employed. According to Daskin's theory, the $p$-median is under the branch of median-based models in discrete location problems. Thus, the goal of $p$-median problem is to minimize the weighted average distance between the demand points and service facilities [8]. The mathematical model of $p$-median problem is given as follows:

$$
\text { Minimize } \quad \sum_{i \in I} \sum_{j \in J} h_{i} d_{i j} Y_{i j}
$$

Subject to:

$$
\begin{aligned}
& \sum_{j \in J} Y_{i j}=1, \forall i \in I \\
& \sum_{j \in J} x_{j}=P \\
& Y_{i j} \leq x_{j}, \forall i \in I ; j \in J \\
& x_{j}=\{0,1\}, \forall j \in J \\
& Y_{i j}=\{0,1\}, \forall i \in I ; \forall j \in J \\
& 0 \leq Y_{i j} \leq 1, \forall i \in I ; \forall j \in J
\end{aligned}
$$

Herein, $I$ denotes the total number of demand points, and $h_{i}$ denotes demand at point $i$. $d_{i j}$ represents travel distance between point $i$ and $j . P$ denotes the number of facility to be located. $Y_{i j}$ and $x_{j}$ are binary variables, $Y_{i j}$ determines if demand point $i$ is assigned to a facility at candidate $j$, and $x_{j}$ determines if a facility is located at candidate $j$.

In the $p$-median location model, the objective function Eq. (10) minimizes the total weighted distance between demand points and service facilities. Eq. (11) ensures that every demand node is assigned, while Eq. (13) limits assignment to open or selected sites. Eq. (12) determines there are $\mathrm{P}$ facilities are going to be located. Eq. (14) and Eq. (15) ensure that integer condition is met. Eq. (16) can be transformed from Eq. (15) since every demand node is going to be assigned to the closest open site automatically in any possible solution.

\section{Comparison of the three location models}

In set covering location model, the number of facility is unlimited, but every demand point is required to be covered and a coverage distance $d_{s}$ should also be specified. The objective of this model is to find a minimum number of service facilities and their locations, which, in a way, improves the availability of the service network.

In maximal covering location model, the number of potential service facilities can be set and a coverage distance $d_{s}$ need to be specified, but there is no need to cover all the demand points. The maximal covering location model's objective is to maximize the coverage of the weighted customer demand under with limited number of service facilities, which focused on the efficiency of the service network.

In $p$-median location model, similar to maximal covering location model, the number of potential service facilities is fixed; but the coverage distance $d_{s}$ does not need to be specified.
The objective of $p$-median location model is to minimize the overall weighted distance between demand points and service facilities, which focuses on the responsiveness of the service network.

\section{CASE STUDY}

In order to present a deep insight of the location-based analysis and optimization, a real-world case study on postal service is performed in Narvik (a city in northern Norway) so as to improve the performance of postal service network.

\section{A. Overview of the case study}

Narvik is a city in Norland County in Northern Norway, and almost a half part of the city downtown is built along the hillside. According to Google's database in 2012, 18,473 residents live in this city. The map shown in Fig. 2 is from Google map with plotting scale equal to $200 \mathrm{~m}$. Previously, there is one post office located in zone 21 to provide all types of postal service. However, the original post office is divided into two subbranches at zone 20 and zone 26 . The objective of this case study is to investigate the performance of the postal service network at Narvik and provide suggestions for decision-makers for future improvement on availability, efficiency and responsiveness of the postal service.

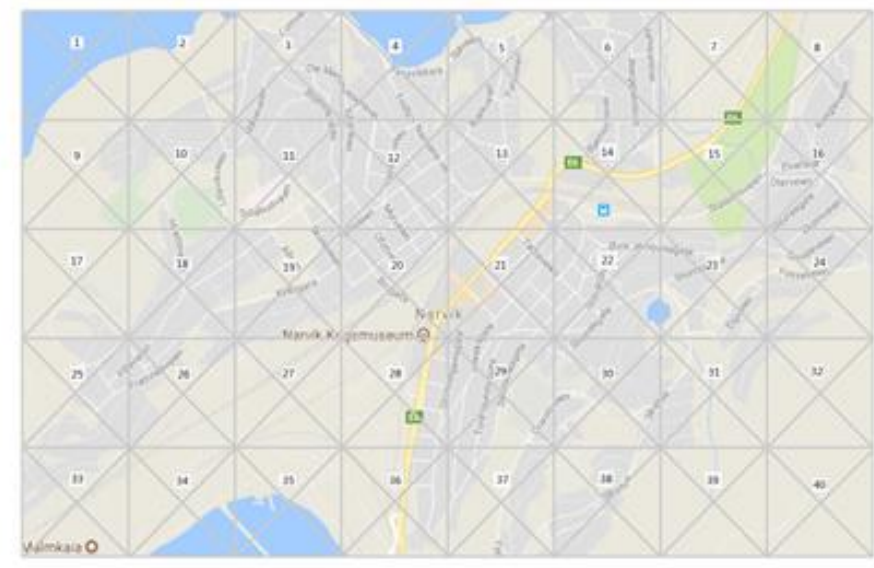

Fig. 2. The map of Narvik city

As shown in Fig. 2, the city area is divided into 40 cells with the same size $(3 \mathrm{~cm} \times 2.9 \mathrm{~cm})$ for simplifying the analysis work. Thus, the total length of map is $24 \mathrm{~cm}$ and height is $14.5 \mathrm{~cm}$. Cells are marked from 1 to 40 in sequence from left to right. The corresponding coordinate system is then established from the lower left corner, which is $(0,0)$. Thus, the center point of cell 33 is (1.5 1.45), and the center points of the other cells can also be determined accordingly. With the information of the coordinates and scale, the distance between different points can easily be calculated. Besides, in this case study, the customer demands of each cell are allocated to the center point in order to simplify the calculation.

\section{B. Critical parameters}

For obtaining the distance matrix, Manhattan metric is used. Manhattan metric is sum of absolute difference between two coordinates and is usually used for distance calculation for 
transportation problems in city downtown. The formula for measuring distance between $\mathrm{p} 1$ at $(\mathrm{x} 1, \mathrm{y} 1)$ and $\mathrm{p} 2$ at $(\mathrm{x} 2, \mathrm{y} 2)$ with Manhattan metric is:

$$
|\mathrm{x} 1-\mathrm{x} 2|+|\mathrm{y} 1-\mathrm{y} 2|
$$

However, it is unnecessary to calculate the real distance between all the pairs of the 40 points. Table I. represents the number of 40 cells in the city map. As shown in the table, zones marked with " $x$ " are not considered, because they are mountain, sea area or covered less than $20 \%$ of residence area. By applying the plotting scale equal to $200 \mathrm{~m}$, the largest distance is between point " 8 " and " 33 " which is $4347 \mathrm{~m}$. Furthermore

TABLE I. The EXcluded Points In The CASE Study

\begin{tabular}{|c|c|c|c|c|c|c|c|}
\hline $1(\mathrm{x})$ & $2(\mathrm{x})$ & 3 & 4 & 5 & 6 & 7 & 8 \\
\hline $9(\mathrm{x})$ & 10 & 11 & 12 & 13 & 14 & $15(\mathrm{x})$ & 16 \\
\hline $17(\mathrm{x})$ & 18 & 19 & 20 & 21 & 22 & 23 & 24 \\
\hline 25 & 26 & $27(\mathrm{x})$ & 28 & 29 & 30 & 31 & $32(\mathrm{x})$ \\
\hline 33 & $34(\mathrm{x})$ & $35(\mathrm{x})$ & $36(\mathrm{x})$ & $37(\mathrm{x})$ & 38 & $39(\mathrm{x})$ & $40(\mathrm{x})$ \\
\hline
\end{tabular}

In order to determine the preferred distance by the customers to the post office, a survey with random interviews is performed. And, after inquiring 100 residents randomly, the coverage distance is agreed to be set as 900 meters $\left(d_{s}=900\right)$.

\section{Results and discussion}

Currently, there are two post offices providing all kinds of postal services in Narvik, and the locations of these two post office are at cell 13 and cell 27, respectively. The optimization by applying the three location models for service network design is conducted with the Problem Solver of MS Excel, and the results are given in Table II. As shown in the table, both maximal covering location model and $p$-median location model determine that the sites of post offices in this city should be located at cell 19 and cell 22 when the number of service facility is equal to 2 . In this way, both the efficiency and the responsiveness of the postal service network could be optimized with the two post offices. With the application of set covering location model for this case, the minimum number required for providing a full coverage of customer preferred level of postal service is 5 .

TABLE II. OPTIMIZATION RESULT OF CHANGING NUMBERS WITH MCLP AND P-MEDIAN MODELS

\begin{tabular}{|c|c|c|c|}
\hline $\begin{array}{c}\text { Facility } \\
\text { Numbers }\end{array}$ & $\begin{array}{c}\text { Covering } \\
\text { Model }\end{array}$ & $\begin{array}{c}\text { Coverage } \\
\text { Distance } \\
\text { Specified }\end{array}$ & Facility Locations \\
\hline \multirow{2}{*}{1} & MCLP & 900 & 21 \\
\cline { 2 - 4 } & P-median & - & 21 \\
\hline \multirow{2}{*}{2} & MCLP & 900 & 19,22 \\
\cline { 2 - 4 } & P-median & - & 19,22 \\
\hline \multirow{2}{*}{3} & MCLP & 900 & $12,22,26$ \\
\cline { 2 - 4 } & P-median & - & $12,22,18$ \\
\hline \multirow{3}{*}{4} & MCLP & 900 & $8,12,25,31$ \\
\cline { 2 - 4 } & P-median & - & $12,16,18,22$ \\
\hline \multirow{3}{*}{5} & MCLP & 900 & $6,19,23,26,31$ \\
\cline { 2 - 4 } & P-median & - & $6,12,18,23,29$ \\
\cline { 2 - 4 } & SCLP & 900 & $8,10,13,26,31$ \\
\hline
\end{tabular}

A test with changing number of post offices for maximal covering model and p-median model is also given in Table II. As shown in the result, it is interesting to see that the solution is best when one post office is installed, and this is at zone 21 . The optimal solutions in this case illustrate that the current locations of the two post offices can be significantly improved in terms of availability, efficiency and responsiveness of service network.

\section{CONCLUSION}

This study has presented a location-based analysis and optimization with the help of three well-known facility location problems for service network design (set covering location model, maximal covering location model and $p$-median location model), and real-world case study on postal service in Narvik is performed for illustrating the application of the methods. The result shows the optimal locations of the post offices with respect to different focuses: availability, efficiency and responsiveness, respectively. Furthermore, the obtained results also illustrates the performance of current postal service network in Narvik can be improved by relocating the two post offices. Future research will be conducted for a detailed and deep comparison between the optimal results of the three facility location models.

\section{ACKNOWLEDAGEMENT}

The research is supported by TARGET project financed under NPA Programme.

\section{REFERENCES}

[1] Grégoire, B., \& Schmitt, M. (2006, June). Business service network design: from business model to an integrated multi-partner business transaction. In E-Commerce Technology, 2006. The 8th IEEE International Conference on and Enterprise Computing, E-Commerce, and E-Services, The 3rd IEEE International Conference on (pp. 84-84). IEEE.

[2] S. Chopra and P. Meindl, Supply Chain Management: Strategy, Planning, and Operation (5th Edition), New Jersey: Pearson Education, 2013.

[3] Yu, H., Solvang, W. D., \& Yang, J. (2014). Improving Accessibility and Efficiency of Service Facility through Location-based Approach: A Case Study at Narvik University College. Advanced Materials Research, (1039).

[4] Weber, A. (1929). Theory of the Location of Industries [translated by CJ Friedrich from Weber's 1909 book]

[5] Daskin, M. S. (2011). Network and discrete location: models, algorithms, and applications. John Wiley \& Sons.

[6] Brimberg, J., Hansen, P., Mladonovic, N., \& Salhi, S. (2008). A survey of solution methods for the continuous location allocation problem. International Journal of Operations Research, 5(1), 1-12.

[7] Daskin, M. S. (2008). What you should know about location modeling. Naval Research Logistics (NRL), 55(4), 283-294.

[8] Current, J., Daskin, M., \& Schilling, D. (2002). Discrete network location models. Facility location: applications and theory, 1, 81-118.

[9] Daskin, M. S., \& Dean, L. K. (2005). Location of health care facilities. Operations research and health care, 43-76.

[10] Fo, A. R. A. V., \& da Silva Mota, I. (2012). Optimization models in the location of healthcare facilities: a real case in Brazil. Journal of Applied Operational Research, 4(1), 37-50.

[11] Brotcorne, L., Laporte, G., \& Semet, F. (2003). Ambulance location and relocation models. European journal of operational research, 147(3), 451463.

[12] Ordonez, F., Dessouky, M. M., \& Jia, H. (2005). A Modeling Framework For Facility Location Of Medical Services for Large-Scale Emergencies. 
[13] Baray, J., \& Cliquet, G. (2013). Optimizing locations through a maximum covering/p-median hierarchical model: Maternity hospitals in France. Journal of Business Research, 66(1), 127-132.

[14] Jia, H., Ordóñez, F., \& Dessouky, M. M. (2007). Solution approaches for facility location of medical supplies for large-scale emergencies. Computers \& Industrial Engineering, 52(2), 257-276.

[15] Shariff, S. R., Moin, N. H., \& Omar, M. (2012). Location allocation modeling for healthcare facility planning in Malaysia. Computers \& Industrial Engineering, 62(4), 1000-1010.

[16] Dawson, M. C. (2005). Minimizing security forces response times through the use of facility location methodologies (No. AFIT/GLM/ENS/05-05). AIR FORCE INST OF TECH WRIGHTPATTERSON AFB OH SCHOOL OF ENGINEERING AND MANAGEMENT.

[17] Bell, J. E., Griffis, S. E., Cunningham, W. A., \& Eberlan, J. A. (2011) Location optimization of strategic alert sites for homeland defense. Omega, 39(2), 151-158.

[18] Erdemir, E. T., Batta, R., Spielman, S., Rogerson, P. A., Blatt, A., \& Flanigan, M. (2008). Location coverage models with demand originating from nodes and paths: application to cellular network design. European journal of operational research, 190(3), 610-632.

[19] Batta, R., \& Mannur, N. R. (1990). Covering-location models for emergency situations that require multiple response units. Management science, 36(1), 16-23.

[20] Curtin, K. M., Hayslett-McCall, K., \& Qiu, F. (2010). Determining optimal police patrol areas with maximal covering and backup covering location models. Networks and Spatial Economics, 10(1), 125-145.

[21] Balcik, B., \& Beamon, B. M. (2008). Facility location in humanitarian relief. International Journal of Logistics, 11(2), 101-121.

[22] Toregas, C., Swain, R., ReVelle, C., \& Bergman, L. (1971). The location of emergency service facilities. Operations research, 19(6), 1363-1373.

[23] Šarac, D., Kopić, M., Mostarac, K., Kujačić, M., \& Jovanović, B. (2016). Application of Set Covering Location Problem for Organizing the Public Postal Network. PROMET-Traffic\&Transportation, 28(4), 403-413.
[24] Nozick, L. K., \& Turnquist, M. A. (2001). Inventory, transportation, service quality and the location of distribution centers. European Journal of Operational Research, 129(2), 362-371.

[25] Madleňák, R., Madleňáková, L., Štefunko, J., \& Keil, R. (2016). Multiple approaches of solving allocation problems on postal transportation network in conditions of large countries. Transport and Telecommunication Journal, 17(3), 222-230.

[26] Dantrakul, S., Likasiri, C., \& Pongvuthithum, R. (2014). Applied pmedian and p-center algorithms for facility location problems. Expert Systems with Applications, 41(8), 3596-3604.

[27] García-Palomares, J. C., Gutiérrez, J., \& Latorre, M. (2012). Optimizing the location of stations in bike-sharing programs: a GIS approach. Applied Geography, 35(1), 235-246.

[28] Nozick, L. K., \& Turnquist, M. A. (1998). Integrating inventory impacts into a fixed-charge model for locating distribution centers. Transportation Research Part E: Logistics and Transportation Review, 34(3), 173-186.

[29] Murray, A. T., \& Gerrard, R. A. (1997). Capacitated service and regional constraints in location-allocation modeling. Location science, 5(2), 103 118.

[30] Eberlan, J. A. (2004). Location optimization of continental United States strip alert sites supporting homeland defense (No. AFIT/GLM/ENS/0402). AIR FORCE INST OF TECH WRIGHT-PATTERSON AFB OH DEPT OF OPERATIONAL SCIENCES.

[31] Owen, S. H., \& Daskin, M. S. (1998). Strategic facility location: A review. European journal of operational research, 111(3), 423-447.

[32] Erkut, E. (1990). The discrete p-dispersion problem. European Journal of Operational Research, 46(1), 48-60.

[33] Kuby, M. J. (1987). Programming Models for Facility Dispersion: The pDispersion and Maxisum Dispersion Problems. Geographical Analysis, 19(4), 315-329.

[34] Rahman, S. U., \& Smith, D. K. (2000). Use of location-allocation models in health service development planning in developing nations. European Journal of Operational Research, 123(3), 437-452.

[35] Church, R., \& Velle, C. R. (1974). The maximal covering location problem. Papers in regional science, 32(1), 101-118. 